Bol. Acad. peru. leng. 65. 2019 (129-149)

\title{
LA MASCULINIZACIÓN DEL LENGUAJE FEMENINO EN PELÍCULAS Y MONÓLOGOS PERUANOS
}

\section{THE MASCULINIZATION OF THE FEMININE LANGUAGE IN PERUVIAN FILMS AND MONOLOGUES}

\author{
Alexis Fernando Gutiérrez Luyo \\ Marco Antonio Lovón Cueva \\ Universidad Nacional Mayor de San Marcos
}

\section{Resumen:}

La masculinización del lenguaje femenino es un tema que ha sido poco investigado. El presente artículo tiene por objetivo principal explicar el fenómeno de la masculinización que se presenta en el lenguaje de las mujeres en el Perú, recreado en espacios como el cine y los monólogos. Metodológicamente, se examina la utilización de palabras y frases masculinizadas proferidas por las mujeres en dos películas y dos monólogos (stand up comedy). En el trabajo se concluye que el habla masculinizada responde a la perfomance del sujeto en relación con determinados contextos situacionales y sociales.

\section{Abstract:}

The masculinization of the feminine language is an issue with little research. The main objective of this paper is to explain the phenomenon of masculinization that occurs in the language of women in Peru, recreated 
https://doi.org/10.46744/bapl.201901.007

in spaces such as cinemas and monologues. From a methodological point of view, we examine the use of masculinized words and phrases proffered by women in two films and two monologues (stand up comedy). The paper concludes that masculinized speech responds to the performance of the subject in relation to certain situational and social contexts.

Palabras clave: masculinización, lenguaje femenino, léxico, contexto, sociolingüística.

Key words: masculinization, feminine language, lexicon, context, sociolinguistics.

Fecha de recepción: $\quad$ 09/03/2019

Fecha de aceptación: $\quad 31 / 05 / 2019$

\section{Introducción}

En diversas culturas, se sostiene que el habla femenina se diferencia de la masculina por el léxico o la pronunciación, e incluso por el tipo de temas y gestos que acompañan el discurso. Sin embargo, la diferenciación no es absoluta, por ejemplo, los supuestos vocablos atribuidos únicamente a hombres pueden ser usados por las mujeres y viceversa, a no ser que la comunidad prohíba esa interacción o mezcla y establezca fronteras. El reconocimiento de que existe un habla femenina y un habla masculina responde a las percepciones que tienen los hablantes en comunidad (Apaza, 2014). Las mujeres buscan construir su imagen de mujer o representarse como tal a través no solo de la vestimenta, el peinado, los colores, sino también a través de sus formas de hablar y de temas de qué hablar; lo propio ocurre con los varones (Castellanos, 1995). Estas prácticas de hablar como mujeres y hombres se fuerzan por los patrones familiares, cuando la madre o el padre moldean el habla del hijo (en algunas familias se suele escuchar: «Mi hijo habla como un verdadero hombre»). En otras palabras, en comunidad se socializan las maneras de usar el lenguaje. A los hombres 
https://doi.org/10.46744/bapl.201901.007

no solo se les enseña a escupir, gritar o ser el macho alfa, sino también a cómo usar la voz, cómo imponerse, cómo ser feroz, cómo insultar. Las enseñanzas no solo ocurren dentro de espacios privados, como la familia, sino también a través de los espacios públicos, como la escuela, en donde a través de la interacción con los pares de género, o a través de las relaciones jerárquicas en los que se ven envueltos, se asimila y se reproduce el discurso de cómo se debe hablar (en algunas escuelas se les dice a las niñas: «Modula tu habla» o «Sé más femenina»). «[...]. La idea de que el lenguaje de las mujeres es más cortés, más refinado —en una palabra: más femenino- - es generalizada y se ha mantenido vigente durante muchos siglos» (Coates, 2009:37). Culturalmente, incluso, las formas de hablar «indebidas» se censuran con frases como «así no debe de hablar una señorita» o «los hombres hablan como varones, no como hembras». Asimismo, en diversas culturas, se valora que el hombre hable «masculinamente», es decir, mientras más groserías y vulgaridades, es más varón y más temido. En Mujeres, hombres y lenguaje: Un acercamiento sociolingüístico a las diferencias de género, de Coates (2009), se indica que el uso del lenguaje vulgar es muy frecuente en los hombres y que las mujeres se caracterizan más bien por el habla formal. A las mujeres se les atribuye el cuidado del habla, hasta incluso la sobrevivencia de la lengua.

En el Perú, hemos percibido que algunas mujeres jóvenes emplean cada vez más groserías atribuidas como propias del habla de varones. La expresión «no seas huevón», que suele emplearse entre hombres, es usada por algunas jóvenes hacia sus compañeros varones. Otras son «calla, cabro», "me llega al pincho» (aunque ellas no tengan pene), «habla, causa», «vete a la mierda, o(y)e» o «no jodas, mierda». Estas maneras de hablar son asimiladas por ellas, creemos, para empoderarse en el discurso, pues la sociedad peruana, sobre todos los grupos juveniles, es muy machista. Incluso sus compañeras mujeres lo son. Masculinizar el habla femenina es producto de una construcción discursiva, planificada o de forma espontánea. Las mujeres que van masculinizando su habla en determinados momentos ganan automaticidad o práctica, por lo que emplean dicho registro en contextos similares, es decir, en situaciones de necesidad, de manera natural. Los hombres, por su parte, parecen aceptar tal forma de hablar y pueden dialogar con ese tipo de habla. 
https://doi.org/10.46744/bapl.201901.007

La masculinización del habla femenina no ha sido estudiada con detenimiento o es muy cuestionada. Es necesario indicar que hay pocas fuentes bibliográficas que abordan el tema como eje central. Por lo general, se encuentran textos que refieren a la diferenciación entre el habla femenina y masculina.

Por eso, motiva realizar esta investigación como un acercamiento a este tipo de registro lingüístico.

El artículo sitúa el estudio como un tema de corte sociolingüístico y pragmático porque los componentes o el objeto de estudio están condicionados por factores extralingüísticos: la masculinización del habla femenina se relaciona con las variables sociales como el género, la clase social y la edad; así como con los conceptos de la pragmática, por ejemplo, el contexto y la especificidad del tema (el tópico de la conversación).

La investigación se organiza de la siguiente manera: presenta una introducción, un marco teórico, una metodología, un análisis y unas conclusiones.

\section{Los estudios sociolingüísticos y pragmáticos}

La sociolingüística estudia al lenguaje en su forma funcional en correlación con sus aspectos socioculturales. Los grandes investigadores de este campo son W. Labov, R. A. Hudson, A. Fishman y D. Hymes, quienes con sus investigaciones han consolidado a la sociolingüística como una ciencia. Posteriormente, dentro del campo de lengua y sociedad se han insertado los análisis del discurso realizados por T. van Dijk, N. Fairclough, M. Foucault. La sociolingüística ha dado hasta ahora importancia al estudio del lenguaje, las lenguas, las variedades, los registros en relación con las sociedades, grupos sociales, contextos socioculturales, interacciones sociales.

En este campo, importa estudiar las variables sociolingüísticas. Para Virginia Zavala, la variedad social no solo se restringe a la variación del lenguaje por clase social, que es una de las tantas variables; hay otras 
variables como las de género, grupo étnico, diferencias generacionales (Pérez, 2004). Estas variedades no deben de verse de forma independiente, sino de forma agrupada e interactiva, porque trabajan de forma conjunta para generar más variedades lingüísticas de una lengua.

La variable género recoge las características de los hombres y de las mujeres en la descripción lingüística, pero también de los homosexuales, las lesbianas, etc. Nuestra sociedad actual se ha visto inmersa en la inclusión y aceptación de nuevos géneros (la concepción de género en el mundo no es global). Los estudios lingüísticos referidos a la comunidad LGTBI o a los grupos transgéneros son pocos emprendidos; por eso, no hay muchas investigaciones sobre sus formas de hablar o apropiarse del lenguaje.

La variable edad refiere a la diferenciación lingüística por la cantidad de años de vida que tienen los hablantes de una sociedad. Con esta variable se diferencian el habla de los niños con la de los adolescentes, la de los jóvenes con la de los adultos, etc. Es una de las variables más interesantes para la sociolingüística, dado que es totalmente determinante para la diferenciación lingüística; como una variable social, está en interrelación con las demás variables, por lo que tiene implicaciones sociales, psicológicas y económicas (Arieza, Cisneros \& Tabares, 2012).

Entre otras, está la variable de clase social. Los hablantes suelen hablar según el estrato o grupo social al que pertenecen. Hay una percepción de que se habla por pertenecer a un estrato económico más superior que otro. Por ejemplo, en el Perú, se cree que existe un habla de la élite social o de grupos económicos ricos, incluso se ha llegado a hablar de un "habla pituca», o de las esferas altas, la cual muchas veces se ridiculiza por los sujetos sociales que no forman parte de este grupo.

También se encuentra la variable situacional. La situación condiciona las formas de hablar de las personas: no es lo mismo hablar frente a un rector de una universidad que hablar con un trabajador informal o un padre de familia sobre un tema en cuestión. Los hablantes 
modulan su habla en relación a la situación, con quienes se encuentren conversando.

Una disciplina con la que se relaciona la sociolingüística es la pragmática. Esta tiene como objeto de estudio el comportamiento de los interlocutores de una lengua en un contexto determinado. Fernández (1999: 238) señala que la pragmática es «la disciplina que se interesa por los aspectos, factores y componentes que intervienen en la efectividad y en el éxito de la interacción comunicativa» (Arieza, Cisneros \& Tabares, 2012). Entonces, la pragmática, al igual que la sociolingüística, estudia al lenguaje en su forma funcional: se prioriza el contexto, lo situacional de una conversación. Este campo también cuenta con grandes representantes como P. Grice, J. Austin, J. Searle, Ch. Pierce, etc.

Un concepto importante en pragmática es el contexto, dado que es a través de este concepto que podemos comprender una gran cantidad de enunciados que no guardan un significado totalmente literal, a consecuencia de que están sujetos a las situaciones contextuales. Se define como la circunstancia, el escenario, la realidad en la que se desarrolla una conversación de dos hablantes. La definición es muy amplia porque depende del emisor o el receptor, lo que hace que existan tipos de contextos: por ejemplo, el contexto social que es propio de un grupo social; o sea, solo ese grupo puede entenderlo. A la pragmática le interesa cómo se usa la lengua para determinados propósitos.

\section{La masculinización del lenguaje femenino}

Se entiende por la masculinización del lenguaje femenino al fenómeno de utilización de términos y frases que suelen ser propias o privativas de los hombres por parte de las mujeres. La idea de la diferenciación surge de los trabajos en los que se plantea la diferenciación entre el lenguaje femenino y el masculino; la diferenciación hizo que en años posteriores, gracias a la evolución en el aspecto social de la mujer (la igualdad de géneros), existiera una mayor confluencia entre los hombres y las mujeres, o sea que estuvieran en mayor contacto, se relacionaran en 
https://doi.org/10.46744/bapl.201901.007

el ámbito laboral, político, etc. Por lo tanto, nuestro enfoque es dinámico (es uno de los enfoques lingüísticos para estudiar el lenguaje y el género) porque se "pone énfasis al aspecto dinámico de la interacción» (Coates, 2009:27). Entonces, la interacción actual entre los hombres y las mujeres hizo que surgiera la pregunta de si su lenguaje ha cambiado, si la distinción tradicional aún se mantiene, y también si sus hablas se han visto influenciadas entre sí.

Desde una edad muy temprana, los niños y niñas están influenciados por las normas sociales, ya que son educados por los padres, quienes cumplen una serie de pautas establecidas que hacen que se diferencien en su comportamiento y lenguaje (Arieza, Cisneros \& Tabares, 2012). Por lo tanto, son los aspectos sociales y no los biológicos los que determinan la diferenciación (Tusón, 2016). Las mujeres suelen ser educadas para hablar más lento o calmadas. Según Diez (2001:64), otro rasgo del habla femenino es la cordialidad. Las mujeres se han caracterizado por tener un lenguaje más cordial que el de los hombres, no solo en referencia al lenguaje formal, sino también a la mayor cooperación en una conversación y en proferir un mayor número de cumplidos y disculpas. Los hombres, por su parte, tienden a usar groserías y a referirse a otros hombres como «cuñado» y «compadre». Las mujeres, en contraste, no suelen proferir lisuras ni aquellos vocablos, pero esto no es una generalización, ya que una mujer puede decir tales vocablos con naturalidad y no afectará en nada a la sociedad. Asimismo, Arieza, Cisneros \& Tabares (2012) mencionan que las mujeres evitan nombrar ciertas partes del cuerpo (los genitales del hombre y el de ellas mismas), ciertas necesidades naturales de las personas (ir al baño) y enfermedades, por lo que optan por los eufemismos; en cambio, los hombres suelen referirse a estas de forma directa y espontánea. Coates (2009) cita a Jespersen para señalar que la utilización de adverbios es más frecuente en las mujeres; en seguida la misma autora (2009) cita uno de los comentarios de lord Chesterfield quien pone de ejemplo al adverbio infinitamente y señala que se trata de un rasgo distintivo de la mujer, ya que ellas tienen gusto por la utilización de las hipérboles y esa es la razón para establecer un mayor uso de los adverbios que adicionan intensidad. Lakoff (1973) señala 
que el adverbio tan (so, en inglés) es propio de las mujeres, pero no impide que no pueda ser de uso masculino. Por otra parte, hay una conceptualización estereotipada de las mujeres, y es que se las ve como habladoras y charlatanas. Esto responde a una serie de estereotipos sobre la mujer, que no son verdaderamente ciertos (Diez, 2001).

Lo anterior es la visión tradicional del lenguaje de la mujer. Arieza, Cisneros \& Tabares (2012) citan a Henao y Castañeda (2001:18-19) porque ambos autores mostraron inquietud por la utilización femenina de expresiones que en años anteriores era de uso exclusivo de los hombres y que, por lo general, solo eran emitidas por las mujeres jóvenes. Entonces, se puede plantear que la masculinización del lenguaje femenino se da entre mujeres de la década actual (siglo xxi). Los nuevos usos de términos masculinos, por parte de las mujeres, se deben al empoderamiento que han ejercido, debido a que en la actualidad la mujer tiene más voz y el derecho de igualdad entre hombres y mujeres está más acatado.

Sin embargo, no solo es posible encontrar una apreciación sobre la dualidad lingüística asociada al habla, es decir, no solo se percibe que existe un habla masculina y una femenina, con las atribuciones que reciben, sino también es posible encontrar una cuatripartición lingüística en las sociedades: un habla femenina, un habla masculina, un habla femenina masculinizada y un habla masculina feminizada, las cuales muestran la variedad de cómo se percibe y se construye el lenguaje en sociedad.

En el texto Sociolingüística: Enfoques pragmático y variacionista, los autores Areiza, Cisneros y Tabares (2012) citan a Henao y Castañeda (2001) para indicar que la utilización de términos o expresiones típicas de los hombres empezaron a proferirse por mujeres debido al ambiente socioeconómico y sociocultural que compartían. Las mujeres «masculinizan» su habla porque tienen que nivelar su forma de hablar a la de los hombres, no solo usar el lenguaje gerencial o empresarial; además, tienen que usar el lenguaje grotesco, varonil, plagado de jergas, si tienen que «entrar en onda», ser reconocidas, recibir atención, 
ser vistas como igual o ser aceptadas, incluso, como sujetos sociales superiores en su rango de jefa de varones. La supuesta habla femenina se masculiniza. Lo mismo ocurre con los hombres.

Los varones pueden feminizar su forma de hablar, ser más delicados, más suaves, más pausados, porque el mundo laboral se los exige inconscientemente. En atención al cliente, los trabajadores varones pueden «feminizar» su forma de hablar para convencer al cliente, generalmente femenino, acerca de la adquisición de un producto. En la escuela, los profesores a veces modulan sus maneras de hablar ante sus alumnas o alumnos si buscan verse más maternales, sobre todo si su público es menor de edad, o esperan de él un habla como tal.

Sin embargo, la masculinización del habla femenina no solo ocurre en estos tiempos por la influencia del entorno laboral (Yépez, 2005); más bien, al parecer, ocurre por una presión social, que influye en las mujeres hablar de forma «varonil» o «achorarse», porque la situación y los temas seleccionados en el discurso lo ameritan. Ellas no quieren verse como débiles verbalmente ante los hombres ni otras mujeres. Los hablantes, por tanto, proyectan y construyen sus formas de emplear el lenguaje por voluntad propia, por el contexto o la situación, por quién es su destinatario, por la necesidad de conseguir algo, o por tratar de imponerse o posicionarse socialmente.

Masculinizar el habla femenina es cambiar a un registro más varonil: usar groserías, hablar como hombre, hablar poco, «hablar más cool».

\section{Metodología}

Para analizar la masculinización del habla femenina, se escogieron dos películas peruanas: la primera fue No me digas solterona (2018) de Ani Alva Helfer, y la segunda, Soltera codiciada (2018), de Bruno Ascenzo y Joanna Lombardi. Además, se seleccionaron dos monólogos (los denominados stand $u p$ ) de mujeres peruanas presentados en el Club de la Comedia (2011): el primero corresponde a Carla Arriola y el segundo, a Oriana Cicconi. El contenido, tanto de las películas como de 
https://doi.org/10.46744/bapl.201901.007

los monólogos, está disponible en la plataforma de videos YouTube. Estos materiales muestran formas pensadas y planificadas de masculinizar a las mujeres, razón por la que trabajamos con tales muestras.

Metodológicamente, se transcriben únicamente los fragmentos en los que se percibió el fenómeno de la masculinización del lenguaje femenino. Las expresiones masculinizadas se resaltan con letra negrita y se especifica el contexto de uso.

\section{Análisis}

\subsection{Análisis de las escenas de las películas}

\subsection{1. «Perra»}

- Escena

Contexto: Llegada de Sol y sus amigas a la casa de Patricia. (...)

Mariana: Hay que chupar mejor, ¿ya?

Amiga 4: No te cansas, ¿no?

Mariana: No, y de tomar tampoco.

Sol, Amiga 4: Oh, que perra, que perra, que perra mi amiga. (...)

Película: No me digas solterona (2018)

En la primera escena, vemos que en el diálogo entre mujeres aparece el insulto "perra» para aludir a chica fácil o persona despreciable, según el DLE (2014). Es usual que un hombre descalifique a una mujer con la expresión "perra», pero lo curioso está en el uso que una mujer hace para llamar a otra mujer como tal. También la expresión «hay que chupar», para referirse a ingerir bebidas alcohólicas (DLE, 2014) y propia del léxico coloquial de los hombres, es usada en la escena, pero con doble sentido: no solo para tomar, sino para realizar sexo oral. 
El contexto es la llegada de Sol y sus amigas a la casa de Patricia, o sea, una reunión de amigas, y el tema que tratan es sobre si deben de tomar alcohol.

\subsection{2. «No jodas» $\mathrm{e}$ «imbécil»}

- Escena

Contexto: Reunión de las cuatro amigas en un local de comida, luego del fin de la relación de Patricia.

(...)

Mariana: El sujeto en cuestión, claramente, es un imbécil y le tiene miedo al compromiso, pero claro, para saber eso no se necesita ser psicóloga.

Amiga 4: Pero bueno, no puede ser un completo imbécil durante 10 años.

Sol: 14 .

Amiga 4: 14 años y con departamento comprado, no me jodas.

Sol: Es que los hombres son así, son unos idiotas, si no se proyectan contigo no se proyectan nunca y después se casan con la primera estúpida que se les cruza. (...)

Película: No me digas solterona (2018)

En esta escena vemos la utilización del vocablo «imbécil», adjetivo que refiere a las personas tontas o faltas de inteligencia (DLE, 2014), empleado dos veces (en ambas ocasiones se refieren al ex de Patricia), y «estúpida», para referir a cualquier jovencita que llegue a ser la nueva pareja del ex de Patricia. El uso de esas palabras es atípico en la mujer, ya que, según Rissel (1981), las mujeres se caracterizan por un habla sin groserías. En la expresión «no me jodas», también se observa la masculinización del lenguaje femenino porque las mujeres evitan el lenguaje informal. Esta expresión es muy propia de los varones peruanos. 
https://doi.org/10.46744/bapl.201901.007

El contexto es la reunión de las cuatro amigas en un local de comida, luego del fin de la relación de Patricia, en la que prevalece la reunión de amigas y el tema es el fin de la relación de Patricia y su ex.

\subsection{3. «Desahuévate» $\mathrm{y}$ «arranca»}

- Escena

Contexto: Patricia se prepara para salir y va de compras, cuando regresa, cruza la pista y casi la atropellan.

Natalia Málaga: Desahuévate pues carajo.

Patricia: Disculpa.

Natalia Málaga: ¿Estás pensando en los huevos del gallo?

Patricia: No, no, no.

Natalia Málaga: ¿Te dejó tu marido?

Patricia: SILENCIO (FINGE LLORAR)

Natalia Málaga: Arranca oye, apura, pava ahí.

Película: No me digas solterona (2018)

En esta escena, observamos el enunciado «desahuévate pues carajo», que se refiere a que vuelva a la realidad, que no esté distraída, y «arranca oye», para exigir que se dé prisa. Son expresiones que, según Diez (2001: 64), se conceptualizan como una influencia masculina. En el Perú, son usadas por los varones, sobre todo cuando necesitan demostrar que nadie se puede tomar libertades sobre uno. En los enunciados de Natalia Málaga se rompe con la noción básica de cordialidad del lenguaje de una mujer.

Sobre el vocablo "pava», este refiere a una persona sosa e incauta (Dle, 2014). Para Arieza, Cisneros \& Tabares (2012), las mujeres evitan llamar a otra mujer de forma despectiva, no existen insultos que la mujer pueda proferir para llamar a otra mujer. Sin embargo, en la masculinización del habla, esto puede ocurrir. Entre los hombres, es común escuchar: «no seas pavo» o «no seas huevón». Las mujeres pueden usar estas expresiones, como «no seas pava»o «no seas huevona», como se verá a continuación. 
El contexto sitúa a Patricia mientras se prepara para salir e ir de compras; cuando regresa, cruza la pista y casi la atropellan. El tema es el reclamo de parte de Natalia Málaga hacia Patricia.

\subsection{4. «Huevona»}

- Escena

Contexto: Patricia y sus amigas salen de fiesta y ven a un grupo de jóvenes.

Chica 1: (AL GRUPO DE CHICAS JÓVENES) Chicos.

Chica 2 del grupo: Huevona, llegaste.

Chico 3 del grupo: Al fin.

Patricia: ¿Qué es esto?, ¿noche de colegio?

(...)

Película: No me digas solterona (2018)

En esta escena, ubicamos la palabra «huevona» que según DLE (2014) refiere a una persona tonta, perezosa o tarda. Esta palabra es escuchada con regularidad entre las mujeres que emplean el registro masculinizado. En la escena, la Chica 2 es quien usa el vocablo para dar mayor impacto a su registro. Esta expresión, al igual que «pava» en la anterior escena, según Arieza, Cisneros \& Tabares (2012) se concibe como una expresión típica del hombre; por ende, al ser proferida por una mujer, su lenguaje se torna masculino.

El contexto es sobre Patricia y sus amigas quienes salen de fiesta y ven a un grupo de jóvenes, o sea, una reunión de jóvenes (en su mayoría mujeres) en una discoteca. El tema es el saludo por parte de las amigas.

\subsection{5. «Te cagaste»}

- Escena

Contexto: Gisela P. llama a su enamorado luego de haber terminado su relación.

$(\ldots)$ 
https://doi.org/10.46744/bapl.201901.007

Gisela P.: ¿En serio no me vas a contestar, Matías? (DE FORMA ESTRIDENTE). Ala, ala, ala, iceso es lo que crees que merezco después de 6 años de relación?! (GRITANDO), bueno te tengo una primicia, Matías: el tamaño ideal no es eso que tú tienes, ¿ya?, el tamaño ideal es otro y es grande, iimbécil, te cagaste! (GRITANDO).

Película: Soltera codiciada (2018)

En esta escena, observamos la expresión «iimbécil, te cagaste!», que se usa en una situación emocional. La expresión se concibe como un insulto o afrenta a otra persona y, por lo general, se usa entre hombres. Según Tusón (2016), las groserías son características propias del hombre.

El contexto se sitúa en la llamada de teléfono. Gisela P. intenta llamar a su enamorado, luego de haber terminado su relación (la llamada no se concreta: Matías no responde). El tema es la insistencia de llamadas de Gisela P. a su ex.

\subsection{6. «De mierda» $\mathrm{y}$ «esas huevadas»}

- Escena

Contexto: Gisela P. se encuentra furiosa porque sus amigas hablaban de su ex.

(...)

Gisela P.: No sé, te juro que no tengo idea. Lo único que tengo en la cabeza es al insecto innombrable ese y como quiero que se le pudra los intestinos y que le salga pus y que no le quede más remedio que llamarme a mí para que yo lo cuide y ahí prepararle su manzanillita caliente para que pueda dormir bien y después me siento mal, y se me drena la dignidad por desearle algo tan malo a alguien que he querido tanto, a quien he amado tanto después me siento peor porque resulta que soy la protagonista de una tragicomedia de mierda donde Dios y el diablo y todas las personas o seres que se encargan 
en el universo de hacerme sentir mal me escupen como un mortero y se burlan de mí, y tú puedes aguantar todas esas huevadas porque claro, tú tienes una panera aquí que no te deja sentir nada, pero yo me voy a quedar sola. (...)

Película: Soltera codiciada (2018)

En esta escena, se emplean tres expresiones. La primera es «una tragicomedia de mierda», en la que se observa el uso de una grosería («mierda») para referirse a tragicomedia. Muy aparte de la lisura y siguiendo el cotexto de la expresión, observamos que las mujeres tienden a exagerar o a maximizar sus estados de ánimo; en lugar de una tragicomedia de mierda, la protagonista pudo decir que le va mal (de forma menos exagerada). En segundo lugar, la expresión «tú puedes aguantar todas esas huevadas», que refiere a que a la joven a quien se dirige puede soportar sus problemas («huevadas»). El insulto rompe la noción de formalidad típica del lenguaje femenino. Por último, en «tú tienes una panera», se quiere mostrar a la mujer («panera») como una acompañante fiel (aquella persona que siempre estará a su lado; el vocablo hace referencia a panero, en su forma femenina).

El contexto muestra a Gisela P. furiosa porque sus amigas hablaban de su ex. Esto constituye un estado de tristeza en la protagonista que es expresado a través de gritos y lisuras. El tema que se trata está relacionado a la sexualidad: habla del ex como alguien que no tiene el miembro viril grande (actitud de despecho hacia él).

\subsection{Análisis de los monólogos}

\subsection{1. «Te me haces la angosta» $\mathrm{y}$ «chupa»}

- Monólogo

Tema: Borrachera femenina

Dicen que no hay mujer fea, sino que falta trago, pero cuando todo ese trago se lo toma una mujer, una se pone bien fea, ¿por 
https://doi.org/10.46744/bapl.201901.007

qué?, porque pasas de: salud amiga, porque somos chicas lindas y buenas y todo nos tiene que ir super regio, a: salud pues chata, ¿qué?, ¿cómo que no quieres seguir tomando?, ahora te me haces la angosta, la del calzón con bod, ya, ya chupa, chupa no más, ah (VOZ LARINGALIZADA), pero a los ojos porque sino siete años de mal sexo y nosotros estamos bien ricas para que nos vayan tirando mal (...).

Monólogo de Carla Arriola en el Club de la Comedia (Perú) (2011)

La comediante recrea su forma de hablar con estas expresiones: «salud pues chata, ¿qué?, ¿cómo que no quieres seguir tomando?, ahora te me haces la angosta». Los hombres suelen usar jergas como «chata» o expresiones ligadas al ámbito sexual como «te me haces la angosta», o en la construcción de su masculinidad profieren «falta trago». El término chato o chata refiere a alguien de baja estatura, pero, además, en las situaciones coloquiales de habla tiene connotación familiar que refiere a «amigo». Al ser de tradición masculina, es más común escuchar «chato» por parte de un hombre que «chata» por parte de una mujer. Diez (2001) estudia términos como compadre y cuñado, los cuales son proferidos por más limeños que limeñas; es decir, son más usados por varones, como el término chato. En «ya, ya chupa, chupa no más, ah (VOZ LARINGALIZADA)», vemos otra vez la utilización de «chupa» (ya explicado anteriormente) y lo resaltante es «ah (VOZ LARINGALIZADA)», ya que la voz laringalizada suele ser típica de los hombres. Esa voz se da cuando las participantes están ebrias, por lo tanto, una manera para la emisión de lisuras (en las mujeres) es la ingesta de alcohol. De esta manera, masculinizan sus conductas y también su habla. $Y$ en «nos vayan tirando mal», se hace referencia a la actividad sexual de forma no satisfactoria para la mujer. Las expresiones sexuales de este tipo no son típicas de las expresiones verbales de una mujer en público.

El tema es la borrachera femenina y el ambiente que evoca la comediante para su historia es la reunión de amigas, posiblemente, en una discoteca. 
https://doi.org/10.46744/bapl.201901.007

\subsection{1. «Maricón» $\mathrm{y}$ «huevonazo»}

- Monólogo

Tema: Mi ex

(...) y pensar que yo le decía que: amor prométeme que siempre vamos a estar juntos, nunca me vas a dejar, ¿no? y nuestro hijo va a tener el mismo nombre que mi bisabuelo, Ermelindo (CON VOZ AGUDA). Y él me decía: sí mi amor, sí, sí gordita sí, sí (CON VOZ GRUESA). ¿Saben que hizo el maricón?, termino conmigo en una y encima por mensaje (...)

(...) o la mejor es, la llamada despistada, esa que agarras el celular y marcas el número de tu ex y dejas, ay, como si no hubiera pasado nada, ino?: Carla alucina que ayer me fui a gótica y me agarré a uno mal, mal, mal. Él sí me hace sentir mujer, no como Pedro que es un huevonazo, ¿Pedro escuchaste todo? (PAUSA DE 3 SEGUNDOS) Señora, ¿Qué tal?

Monólogo de Oriana Cicconi en el Club de la Comedia (Perú) (2011)

En «¿saben que hizo el maricón?», se observa nuevamente una grosería que tiende a incumplir la forma convencionalizada del lenguaje de las mujeres (ya explicado en escenas anteriores). Entre los hombres, «maricón» es usado de forma peyorativa para descalificar a su rival cuando no se trata de un uso apreciativo o familiar (a veces, se usa de manera amical). Algunas mujeres incorporan ese uso despectivo. En «me agarré», se refiere al acto de haber estado en actividad sexual con otra persona que no es su pareja; en la escena, no se percibe incomodidad por el uso de esa expresión, muy usada por los hombres. En la expresión «es un huevonazo», se ve cómo el habla femenina incorpora una jerga en grado sumo. Los aumentativos son muy empleados en el habla masculina, mientras que los diminutivos suelen aparecer en el habla de las mujeres (Tusón, 2016). 
https://doi.org/10.46744/bapl.201901.007

El contexto en el que sucede la historia es la etapa del fin de la relación de una joven y el tema sobresaliente es la búsqueda de venganza, de alguna manera, de la mujer.

\section{Conclusiones}

El habla no es una entidad homogénea. Las maneras en que se hablan, por ejemplo, varían de acuerdo con la situación o los aspectos sociales, es decir, en la interacción social. En ese intercambio, los hablantes despliegan sus identidades sociales.

En el corpus presentado, se ha observado una gran cantidad de términos y expresiones de las mujeres con gran incidencia en las groserías. Los registros del habla femenina masculinizada que se representan en las películas y monólogos son una muestra de lo que sucede en las calles o en la sociedad peruana. Los directores y guionistas de las películas y los monólogos plasman aquello que sucede en la vida cotidiana de las personas. Hay un grupo de mujeres que suelen proferir más lisuras, que buscan asemejarse al habla de los hombres, sobre todo en una sociedad o en un entorno machista. Esto no significa que en otros contextos usen su habla femenina, lo interesante del trabajo es ver que pueden emplear el registro de habla femenina masculinizada. Recurrir a un registro u otro nos hace pensar que se tratan de estrategias discursivas con las cuales los hablantes negocian su imagen en la construcción de sus identidades y relaciones interpersonales.

En cada una de las escenas del análisis se observa los diferentes tipos de contextos: la reunión de amigas, la asistencia a una discoteca y el desenfreno de las mujeres. Según el análisis del corpus, el contexto más recurrente para masculinizar el habla es el de la reunión entre amigas (entre mujeres) porque hay familiaridad, pero a la vez empoderamiento, las mujeres no quieren verse como débiles frente a otras y buscan nivelarse al lenguaje varonil. El factor que ayuda a proferir tales términos es la ingesta de alcohol por parte de ellas. Entre los temas donde el habla femenina se masculiniza están los siguientes: la expareja, cuando se trata 
de criticarlo u ofenderlo; el fin de la relación amorosa; el reclamo de algún aspecto de la sociedad que no les gusta. Estos temas pueden afectar el habla y modularlo a un registro más grosero. 
https://doi.org/10.46744/bapl.201901.007

\section{BIBLIOGRAFÍA}

APAZA, I. (2014). Diferencias sociales entre el habla masculina y el habla femenina. Estudios bolivianos, 21.

ARIEZA, R., CISNEROS, M. \& TABARES, L. E. (2012). Sociolingüística: enfoques pragmáticos y variacioncita. Bogotá-Colombia. Ecoe Ediciones.

CASTELLANOS, G. (1995). ¿Existe la mujer? Género, lenguaje y cultura. En: Género e identidad, ensayos sobre lo femenino y lo masculino, 1.a ed., 39-61. Bogotá: Mundo Editores.

COATES, J. (2009). Mujeres, hombres y lenguaje. Un acercamiento sociolingüístico a las diferencias de género. México: Fondo de Cultura Económica.

DIEZ, S. H. (2001). Discurso, identidad y género en el castellano peruano. Lima: Fondo Editorial de la Pontificia Universidad Católica del Perú. p. 31-66.

LAKOFF, R. (1973). Language and Woman's Place. Language in Society, 2(1), 45-80.

PÉREZ, J. (2004). Las variedades de castellano peruano. En Los castellanos del Perú (41-55). Perú: Programa de Educación Básica de la Cooperación Alemana al Desarrollo PROEDUCA.

REAL ACADEMIA ESPAÑOLA (2014). Diccionario de la lengua española (24. ${ }^{\mathrm{a}}$ ed.).

RISSEL, D. (1981). Diferencias entre el habla femenina y la masculina en español. Thesaurus. Tomo XXXVI, Núm. 2, p. 305-322.

TUSÓN, A. (2016). Lenguaje, interacción y diferencia sexual. Enunciación, 21(1), p. 138-151. 
LA MASCULINIZACIÓN DEL LENGUAJE FEMENINO EN PELÍCULAS Y MONÓLOGOS PERUANOS https://doi.org/10.46744/bapl.201901.007

YÉPEZ, A. (2005). El habla de hombres y mujeres en el trabajo. Espéculo: Revista de Estudios Literario, 30. 